\title{
LAND USER AND LAND COVER MAPS OF EUROPE: A WEBGIS PLATFORM
}

\author{
M. A. Brovelli, F. C. Fahl, M. Minghini, M. E. Molinari * \\ Department of Civil and Environmental Engineering, Politecnico di Milano, Como Campus, Via Valleggio 11, 22100 Como, Italy - \\ (maria.brovelli, fernandocesar.fahl, marco.minghini, moniaelisa.molinari)@polimi.it
}

Commission VII, SpS 10 - FOSS4G: FOSS4G Session (coorganized with OSGeo)

KEY WORDS: Land Use, Land Cover, Web Services, Open Source Software, Open Data, WebGIS

\begin{abstract}
:
This paper presents the methods and implementation processes of a WebGIS platform designed to publish the available land use and land cover maps of Europe at continental scale. The system is built completely on open source infrastructure and open standards. The proposed architecture is based on a server-client model having GeoServer as the map server, Leaflet as the client-side mapping library and the Bootstrap framework at the core of the front-end user interface. The web user interface is designed to have typical features of a desktop GIS (e.g. activate/deactivate layers and order layers by drag and drop actions) and to show specific information on the activated layers (e.g. legend and simplified metadata). Users have the possibility to change the base map from a given list of map providers (e.g. OpenStreetMap and Microsoft Bing) and to control the opacity of each layer to facilitate the comparison with both other land cover layers and the underlying base map. In addition, users can add to the platform any custom layer available through a Web Map Service (WMS) and activate the visualization of photos from popular photo sharing services. This last functionality is provided in order to have a visual assessment of the available land coverages based on other user-generated contents available on the Internet. It is supposed to be a first step towards a calibration/validation service that will be made available in the future.
\end{abstract}

\section{INTRODUCTION}

Land use and land cover (LULC) information is continuously gaining importance as it is required for a number of environmental studies. In recent years a variety of global LULC datasets, mostly obtained from satellite imagery, have been made available to the scientific community and the general public. Although they offer valuable information on LULC status, there are still important challenges for assessing and comparing these datasets, especially considering the discrepancies among these products and the different classification schemes applied (Jung et al., 2006). Moreover, even though there are several scientific papers assessing and comparing the classification accuracy of the available global land cover datasets (Brovelli et al., 2015; Büttner et al., 2012; EEA, 2006; Fritz and See, 2005; Giri et al., 2005; Jung et al., 2006; Kaptué Tchuenté et al., 2011; McCallum et al., 2006; Mora et al., 2014; Pflugmacher et al., 2011), there are few effective and user-friendly tools for visually comparing their similarities and discrepancies (EEA, 2016; ESRI Ireland, 2011; NGCC, 2016).

The present project fits within this context by implementing an open source WebGIS platform (EU-LULC WebGIS) aiming to organize and publish the LULC datasets available in Europe at continental scale.

\section{LAND USE AND LAND COVER DATASETS}

The LULC datasets included in the EU-LULC WebGIS platform are: Global Land Cover 2000 Project; the land use products of the Moderate Resolution Imaging Spectroradiometer (MODIS); the CORINE Land Cover; the GlobCover Land Cover Maps; the Land Cover CCI project; the GlobeLand30; and the European Urban Atlas (see Table 1).

\begin{tabular}{|c|c|c|c|}
\hline $\begin{array}{l}\text { LULC } \\
\text { Dataset }\end{array}$ & Provider & $\begin{array}{l}\text { Temporal } \\
\text { coverage }\end{array}$ & $\begin{array}{l}\text { Resolution/ } \\
\text { Scale }\end{array}$ \\
\hline GLC-2000 & EC-JRC & 2000 & $1 \mathrm{~km}$ \\
\hline CORINE & EEA & $\begin{array}{c}1990,2000 \\
2006 \text { and } \\
2012\end{array}$ & $100 \mathrm{~m}$ \\
\hline GlobCover & ESA & $\begin{array}{c}2004-2006 \\
\text { and } 2009\end{array}$ & $300 \mathrm{~m}$ \\
\hline MODIS & USGS & 2001-2012 & $500 \mathrm{~m}$ \\
\hline CCI project & $\begin{array}{l}\text { ESA / UCL- } \\
\text { Geomatics }\end{array}$ & $\begin{array}{c}2000,2005 \\
\text { and } 2010\end{array}$ & $300 \mathrm{~m}$ \\
\hline GlobeLand30 & NGCC & $\begin{array}{c}2000 \text { and } \\
2010\end{array}$ & $30 \mathrm{~m}$ \\
\hline Urban Atlas & ESA & $\begin{array}{c}2006 \text { and } \\
2012\end{array}$ & $1: 10.000$ \\
\hline
\end{tabular}

Table 1. LULC datasets of Europe at continental scale.

The Global Land Cover 2000 Project (GLC-2000) is a global land cover dataset with $1 \mathrm{~km}$ of spatial resolution produced by the Joint Research Center of the European Commission (ECJRC) based on the VEGA 2000 dataset, which encompasses 14 months of pre-processed daily data acquired by the VEGETATION instrument aboard SPOT 4 satellite between November 1999 and December 2000. The GLC-2000 dataset is divided in 19 sub-products, each of which representing one specific region of the Globe. The land cover classification adopted the UN-LCCS scheme with 22 classes (Bartholomé and Belward, 2005).

The Moderate Resolution Imaging Spectroradiometer - MODIS is a sensor on board the Terra and Aqua satellites, which are in 
orbit since 1999 and 2002, respectively. These satellites orbit the entire Earth's surface every 1 to 2 days and acquire data in 36 spectral bands. The MODIS land use products, which are called MODIS Terra + Aqua Land Cover Type Yearly L3 Global $500 \mathrm{~m}$ SIN Grid, have a temporal coverage of 11 years (from 2001 to 2012) and a spatial resolution of $500 \mathrm{~m}$. They contain five different classification schemes derived from a supervised decision-tree classification method. The dataset selected for the EU-LULC WebGIS was the Land Cover Type 2 (UMD) classification scheme of 2012 (NASA and USGS, 2014).

The CORINE Land Cover, which stands for "Coordination of Information on the Environment", was a programme launched in 1985 by the European Union as a prototype project and later taken over by the European Environmental Agency (EEA). The CORINE land cover maps are available for four different time periods: 1990, 2000, 2006 and 2012, though the last one is still in the validation process. These products were derived from Landsat-5 MSS/TM (1990), Landsat-7 ETM (2000), SPOT-4/5, IRS P6 LISS III (2006), IRS P6 LISS III and RapidEye (2012) imageries. There are three levels of land cover classes: the first level with five classes, the second with 15 classes and the third with 44 classes. These datasets are available as both vector and raster datasets with two spatial resolutions: $100 \times 100 \mathrm{~m}$ and $250 \times 250 \mathrm{~m}$ (EEA, 2014a).

The GlobCover Land Cover Maps were generated by the European Space Agency (ESA) in partnership with other institutions (JRC, EEA, FAO, UNEP, GOFC-GOLD and IGBP) as part of the GLOBCOVER project. The land cover maps were produced based on the $300 \mathrm{~m}$ MERIS sensor on board the ENVISAT satellite mission and are available for two main periods: December 2004 to June 2006 and January to December 2009. These maps have 22 land cover classes (Bontemps et al., 2011).

The Land Cover CCI project was carried out by an international team under the coordination of the Université Catholique de Louvain (ULC) aiming to provide a multi-year land cover dataset to be used as input data for climate models. The result is a 10-year product with three central dates: 2000, 2005 and 2010. In fact, each dataset represents a 5-year period land cover map (1998-2002, 2003-2007 and 2008-2012, respectively). The methodology to produce the land cover maps consisted in the application of a multi-sensor strategy, which included images from AVHRR, SPOT-VGT, MERIS FR and RR, PROBA-V and MODIS composites. The final product is a set of global land cover maps with $300 \mathrm{~m}$ of spatial resolution. The map legend contains 22 classes (1st level) and it is based on the UNLCCS scheme, which is compatible with the GLC2000 and GlobCover products (ESA, 2010).

The GlobeLand30, produced by the National Geomatics Center of China (NGCC), is the first global land cover map at a $30 \mathrm{~m}$ of spatial resolution. The production of this dataset was based on the use of Landsat Thematic Mapper (TM) and Enhanced $\mathrm{TM}$ plus (ETM+) satellite images in combination from images of the Chinese Environmental and Disaster (HJ-1) satellite. The GlobeLand30 contains 10 major land use classes and it is available for years 2000 and 2010 (Brovelli et al., 2015; NGCC, 2014).

The European Urban Atlas, developed as part of the Global Monitoring for Environment and Security Programme (GMES), comprises a set of high-resolution land use maps for 305 large European urban zones, which are areas with more than 100.000 inhabitants (reference year of 2006). The land use datasets are based on multispectral or pan-sharpened images with $2.5 \mathrm{~m}$ of spatial resolution (mainly SPOT 5 or other available VHR imagery). The mapping scale is 1:10.000 and the mapping legend relies on 20 classes, being 17 urban and 3 non-urban classes with minimum accuracy of $85 \%$ and $80 \%$, respectively. The land use maps are only available as a vector data (European Commission, 2011; Montero et al., 2014).

\section{METHODOLOGICAL APPROACH}

\subsection{Design process}

The EU-LULC WebGIS is based on the server-client model and was built on a completely open source infrastructure and open standards. The proposed architecture is composed of three tiers: the data storage, the server-side and the client-side components (see Figure 1).

The data storage is divided in two major elements: the raster data storage, which is a collection of pre-processed GeoTIFF files optimized to increase the web map server performance; and the vector data storage, which is built on the PostgreSQL (http://www.postgresql.org) DBMS with PostGIS (http://www.postgis.org) spatial extension to store the 305 tables of the European Urban Atlas.

The server for publishing the geospatial data was GeoServer (http://geoserver.org), which is an open source server-side software that provides an interoperable infrastructure for managing and integrating the data storage and the web user interface. It handles data from major spatial data sources using open standards. The client side is basically composed by two complementary elements: a map built with the Leaflet (http://leafletjs.com) JavaScript library, which is responsible for rendering the raster and vector layers on modern web browsers; and a web user interface, which is based on a web standard model (HTML5 / JavaScript / CCS3).

The user interface (UI) was built upon the Bootstrap framework (http://getbootstrap.com) and Font Awesome icons (http://fortawesome.github.io/Font-Awesome). It was designed to have a similar navigability of a desktop GIS, where users can activate, order (e.g. drag and drop operation) and modify some of the layers' properties (e.g. opacity). In fact, most of the users' interaction will occur on the left-side panel, which is composed by tree sub-panels: the first is for manipulating the layer list; the second is for displaying the legend and controlling the opacity parameter; and the last is for displaying simplified metadata. The legend and metadata are shown only for the active layers. Users can also change the base map through a list of map providers that are displayed as thumbnails on the left-lower corner of the map frame (see Figure 2).

In addition, it is possible to add external LULC maps or any other geospatial data via Web Map Services (WMS) provided that the user enters a valid GetCapabilities URL address. The results are then parsed via a JavaScript function and rendered by Leaflet. Finally, the users can enable the visualization of geotagged photos from some popular photo sharing services that provide an Application Programming Interface (API) for extracting their data. These services are:

- Flickr (http://flickr.com): probably the most popular image hosting website for sharing personal photos. According to Michel (2016) around 2 million photos are uploaded per day and over 5.26 billion photos were available by the end of 2014.

- Panoramio (http://www.panoramio.com): a popular photo sharing website owned by Google. User submitted photos are published on the platform upon acceptance. The collection currently counts over 90 million photos (Panorank, 2016). 
- Geograph (http://www.geograph.org.uk): a project limited to UK and Ireland which aims to collect geographically representative photographs at each node of a square grid with $1 \mathrm{~km}$ side. At the time of writing (April 2016) the website lists a total of $4,872,461$ photos submitted by 12,525 contributors.

It is out of the scope of this paper to detail the differences in the metadata information that users have to provide when uploading the photos on each of these platforms. Interested readers can check the work of Antoniou et al. (in press).

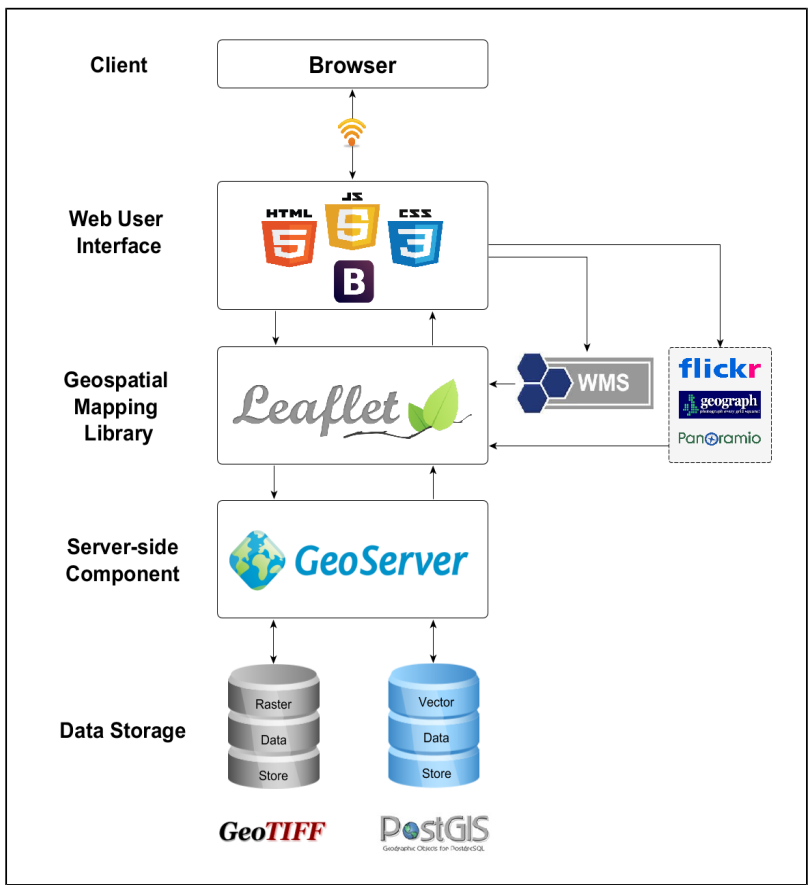

Figure 1. EU-LULC WebGIS architecture

\subsection{Implementation process}

3.2.1 Data processing: The data processing was mostly done using GDAL (http://gdal.org) command line tools and consisted of the following stepwise approach. The first step was the import of the 305 vector files of the European Urban Atlas to the PostgreSQL/PostGIS database. In order to increase the map server performance, an aggregation process (dissolve) was applied to each layer to decrease the number of polygons. The second step consisted in the harmonization of the raster datasets in order to have all the data in the same projection and file format. A series of GDAL utilities were applied in this case, including gdal_translate and gdalwarp. Finally, the last step was implemented to modify the GeoTIFF files in order to increase their performance on GeoServer. The GDAL utilities used were gdalwarp (to create tiled output TIFF files), gdaladdo (to generate internal overviews) and gdal_retile (to generate external overviews or pyramids). The latter was applied only for the biggest files in size, i.e. GlobCover and GlobeLand30 datasets.

Table 2 and Table 3 present information about the native projection, file format and source of the LULC datasets.

3.2.2 Server-side Implementation: GeoServer was deployed under an Apache Tomcat (http://tomcat.apache.org) servlet container. The GlobeLand30 and GlobCover datasets were added to GeoServer using the Pyramid plugin in order to create a mosaic from the TIFF tiles. The Urban Atlas was added as PostGIS database store while the remaining LULC datasets were

\begin{tabular}{|c|c|c|c|}
\hline LC Dataset & $\begin{array}{c}\# \\
\text { Tiles } \\
\end{array}$ & $\begin{array}{c}\text { Original File } \\
\text { Format } \\
\end{array}$ & Source \\
\hline GLC-2000 & 1 & Binary (*.bil) & $\begin{array}{l}\text { European } \\
\text { Commission - } \\
\text { Joint Research } \\
\text { Centre (2003) }\end{array}$ \\
\hline CORINE & 1 & GeoTiff (*.tif) & EEA (2014a) \\
\hline GlobCover & 1 & GeoTiff (*.tif) & ESA (2016) \\
\hline MODIS & 36 & $\begin{array}{l}\text { Hierarchical Data } \\
\text { Format }\left({ }^{*} \text {.hdf) }\right.\end{array}$ & $\begin{array}{l}\text { NASA and } \\
\text { USGS (2014) }\end{array}$ \\
\hline CCI project & 1 & GeoTiff (*.tif) & ESA (2010) \\
\hline GlobeLand 30 & 81 & GeoTiff (*.tif) & NGCC (2014) \\
\hline Urban Atlas & 305 & $\begin{array}{l}\text { ESRI shapefile } \\
(* \text {.shp })\end{array}$ & EEA (2014b) \\
\hline
\end{tabular}

Table 2. Source of the LULC datasets of Europe

\begin{tabular}{|l|l|}
\hline LC Dataset & \multicolumn{1}{|c|}{ Native Projection } \\
\hline GLC-2000 & $\begin{array}{l}\text { Geographic coordinates. Datum WGS84 } \\
\text { ETRS89 / ETRS-LAEA }\end{array}$ \\
GlobCover & $\begin{array}{l}\text { Plate-Carrée with a Geographic Lat/Lon } \\
\text { representation }\end{array}$ \\
MODIS & $\begin{array}{l}\text { Sinusoidal } \\
\text { Plate-Carrée with a Geographic Lat/Lon } \\
\text { representation }\end{array}$ \\
GlobeLand30 & $\begin{array}{l}\text { UTM WGS84 (multiple zones) } \\
\text { Urban Atlas }\end{array}$ \\
\hline
\end{tabular}

Table 3. Native projection of the LULC datasets

added as individual GeoTIFF store. The LULC colour tables were initially generated by using the raster property dialog of the QGIS software (http://qgis.org) and uploaded directly to GeoServer account using the SDL4raster plugin (https://cbsuygulama.wordpress.com/sld4raster-en/).

3.2.3 Client-side Implementation: The LULC raster datasets are served via GeoServer as WMS layers and the vector datasets as WFS layers. These layers are then rendered using Leaflet. Third-party plugins were used to extend the functionality of Leaflet, including a selectable list of base map providers (plugins Leaflet-IconLayers and Leaflet-Providers), an overview map (plugin Leaflet-MiniMap), a navigation bar (plugin Leaflet-NavBar) and a graphical scale bar (plugin LeafletGraphicscale), among others.

The user interface was built upon the latest release of Bootstrap framework in order to include the responsive design concept. It is composed by three main blocks: the header, which is a static panel displaying the logo and the project name; the map block, where the LULC maps are rendered; and the left-side panel, where most of the user interaction occurs (see Figure 2).

The left-side panel is sub-divided in three tabs: layers, legend and metadata. The layers tab shows the list of LULC layers. Users can toggle the visualization and modify the order of the layers using a drag and drop operation. It also allows users to enter a valid GetCapabilites URL in order to display layers from external WMS servers and to toggle the visualization of photos from photo sharing services. The legend tab shows the legend as well as a slider control feature to modify the opacity of each activated layer. The metadata tab shows simplified 
metadata of the displayed layers. The order of the features in these last two tabs are synchronized with the layer order in the first tab. Figure 2 shows a screenshot of the EU-LULC WebGIS layout.

\section{CONCLUSIONS}

The EU-LULC WebGIS is entirely built on open source infrastructure and open standards and enables the visualization of the available LULC maps of Europe at continental level. It also allows users to display WMS layers from external map servers and photos from photo sharing services. The main contribution of our system is to provide a dynamic tool to visually analyse and compare the land use and land cover datasets of Europe in a unique online platform, which can help researchers and professionals involved in related fields.

There is much work in progress to extend and improve the WebGIS. Processing functionalities to quantitatively compare LULC maps and assess their mutual agreement are under development and will be available in the near future. Usercontributed photos are meant to be exploited by users as an ancillary information when working with LULC information, e.g. during calibration, validation and verification processes. There are several problems associated with the use of usercontributed photos as a ground truth LULC information, e.g. the uncertainty of geolocation (which depends on the geolocation service of the user device or results from a manual geolocation); the fact that the LULC classes located behind the photographer (which may differ from the ones being photographed) are not visible; and the fact that, when using the zoom, the object being photographed may be even very far from the geolocation of the photo. However recent studies (see e.g. Antoniou et al., in press) have shown that large percentages of these photos can be considered useful when performing a number of operations on LULC maps.

\section{REFERENCES}

Antoniou, V., Fonte, C. C., See, L., Estima, J., Jokar Arsanjani, J., Lupia, F., Minghini, M., Foody, G., Fritz, S., in press. Investigating the Feasibility of Geo-tagged Photographs as Sources of Land Cover Input Data. ISPRS International Journal of Geo-Information.
Bartholomé, E., Belward, A. S., 2005. GLC2000: a new approach to global land cover mapping from Earth observation data. International Journal of Remote Sensing 26(9), pp. 19591977.

Bontemps, S., Defourny, P., Bogaert, E. Van, Arino, O., Kalogirou, V., Perez, J.R., 2011. GLOBCOVER 2009 Products Description and Validation Report. http://due.esrin.esa.int/files/GLOBCOVER2009_Validation_Re port_2.2.pdf (11 Apr. 2016).

Brovelli, M. A., Molinari, M. E., Hussein, E., Chen, J., Li, R., 2015. The First Comprehensive Accuracy Assessment of GlobeLand30 at a National Level: Methodology and Results. Remote Sensing 7(4), pp. 4191-4212.

Büttner, G., Kosztra, B., Maucha, G., Pataki, R., 2012. Implementation and Achievements of CLC2006, European Environment Agency, Technical Report - Revised Final Draft. Universitat Autònoma de Barcelona: Institute of Geodesy, Cartography and Remote Sensing (FÖMI), Barcelona. http://www.eea.europa.eu/data-and-maps/data/corine-landcover/clc-final-report/clc-final-report/download (11 Apr. 2016).

EEA, 2016. Changing face of Europe. Compare Web Maps with just a swipe. European Environment Agency (EEA). http://discomap.eea.europa.eu/map/EyeOnEarthHome/Template s/eoeswipeviewer/?

appid=beac843098c24924893f62c924564a8c (11 Apr. 2016).

EEA, 2014a. Corine Land Cover 2006 raster data - Version 17 (12/2013). European Environment Agency (EEA). http://www.eea.europa.eu/data-and-maps/data/corine-landcover-2006-raster-3\#tab-gis-data (11 Apr. 2016).

EEA, 2014b. European Urban Atlas - 2006. European Environment Agency (EEA). http://www.eea.europa.eu/dataand-maps/data/urban-atlas\#tab-gis-data (11 Apr. 2016).

EEA, 2006. The Thematic Accuracy of Corine Land Cover 2000. European Environment Agency (EEA). http://www.eea.europa.eu/publications/technical_report_2006 7 (11 Apr. 2016).

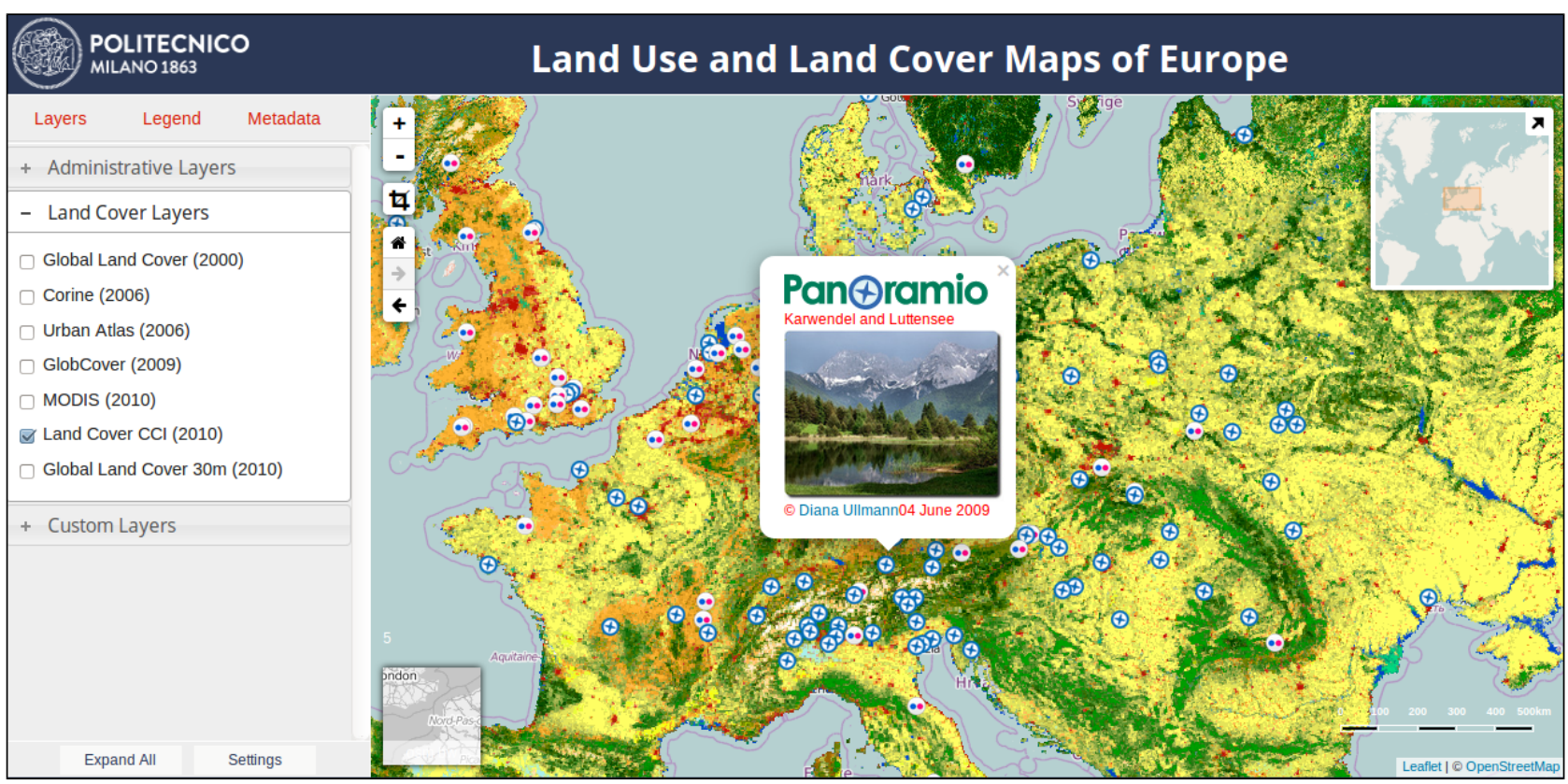

Figure 2. Screenshot of the EU-LULC WebGIS layout. 
ESA, 2010. Three global LC maps for the 2000, 2005 and 2010 epochs. Climate Change Initiative. European Space Agency (ESA). http://www.esa-landcover-cci.org/?q=node/1 (11 Apr. 2016).

ESA, 2016 GlobCover - Global Land Cover Map 2009. European Space Agency (ESA) http://due.esrin.esa.int/page_globcover.php (11 Apr. 2016).

ESRI Ireland, 2011. Corine Land Cover, Ireland. Change Matters. Web Map by Esri Ireland. http://46.137.120.35/CorineCompare/index.html (9 Apr. 2016).

European Commission, 2011. Mapping Guide for a European Urban Atlas. http://www.eea.europa.eu/data-andmaps/data/urban-atlas\#tab-methodology

European Commission - Joint Research Centre, 2003. Global Land Cover 2000 Project (GLC 2000). http://forobs.jrc.ec.europa.eu/products/glc2000/glc2000.php (11 Apr. 2016).

Fritz, S., See, L., 2005. Comparison of land cover maps using fuzzy agreement. International Journal of Geographical Information Science 19(7), pp. 787-807.

Giri, C., Zhu, Z., Reed, B., 2005. A comparative analysis of the Global Land Cover 2000 and MODIS land cover data sets. Remote Sensing of Environment 94(1), pp. 123-132.

Jung, M., Henkel, K., Herold, M., Churkina, G., 2006. Exploiting synergies of global land cover products for carbon cycle modeling. Remote Sensing of Environment 101(4), pp. 534-553.

Kaptué Tchuenté, A. T., Roujean, J.-L., De Jong, S. M., 2011. Comparison and relative quality assessment of the GLC2000, GLOBCOVER, MODIS and ECOCLIMAP land cover data sets at the African continental scale. International Journal of Applied Earth Observation and Geoinformation 13(2), pp. $207-$ 219.

McCallum, I., Obersteiner, M., Nilsson, S., Shvidenko, A., 2006. A spatial comparison of four satellite derived $1 \mathrm{~km}$ global land cover datasets. International Journal of Applied Earth Observation and Geoinformation 8(4), pp. 246-255.

Michel, F., 2016. How many public photos are uploaded to Flickr every day, month, year? https://www.flickr.com/photos/franckmichel/6855169886 (11 Apr. 2016).

Montero, E., Wolvelaer, J. Van, Garzón, A., 2014. The European Urban Atlas. Land Use and Land Cover Mapping in Europe 18, pp. 115-124.

Mora, B., Tsendbazar, N.-E., Herold, M., Arino, O., 2014. Global Land Cover Mapping: Current Status and Future Trends, in: Manakos, I., Braun, M. (Eds.), Land Use and Land Cover Mapping in Europe SE - 2, Remote Sensing and Digital Image Processing. Springer Netherlands, pp. 11-30.

NASA, USGS, 2014. Land Cover Type Yearly L3 Global 0.05Deg CMG. NASA EOSDIS Land Processes DAAC, USGS Earth Resources Observation and Science (EROS) Center. https://lpdaac.usgs.gov/dataset_discovery/modis/modis_product s_table/mcd12c1 (11 Apr. 2016).

NGCC, 2014. GlobeLand30 WebService. The National Geomatics Center of China (NGCC). http://glc30.tianditu.com/index.html (11 Apr. 2016).
NGCC, 2016. GlobeLand30. Validation Tool. The National Geomatics Center of China (NGCC). http://vals.geocompass.com (11 Apr. 2016).

Panorank, 2016. The Panoramio Rankings Web. http://www.panorank.com/index.php?lang=en\&op=global Apr. 2016).

Pflugmacher, D., Krankina, O. N., Cohen, W. B., Friedl, M. A., Sulla-Menashe, D., Kennedy, R. E., Nelson, P., Loboda, T. V., Kuemmerle, T., Dyukarev, E., Elsakov, V., Kharuk, V. I., 2011. Comparison and assessment of coarse resolution land cover maps for Northern Eurasia. Remote Sensing of Environment 115(12), pp. 3539-3553. 